\title{
SISTEMA DE CORTE E TRITURAÇÃO DA CAPOEIRA SEM QUEIMA COMO ALTERNATIVA DE USO DA TERRA, RUMO À SUSTENTABILIDADE FLORESTAL NO NORDESTE PARAENSE*
}

\author{
Sampaio, C. A. ${ }^{1}$ \\ Kato, O. R. ${ }^{2}$ \\ Nascimento-e-Silva, $\mathrm{D}^{3}$
}

\section{Resumo}

A crise relacionada às mudanças climáticas e ao aquecimento global neste início de século é um problema que clama por ações capazes de responder às inquietudes da sociedade. Entre outras ações, o que tem sido reclamado está na forma de gestão e aproveitamento dos recursos naturais. A geração de tecnologia do corte e trituração da capoeira sem queima aponta os caminhos capazes de garantir a segurança das comunidades locais, impedindo a deterioração dos ecossistemas e a degradação humana. No caso da Amazônia, principalmente, configura-se numa das formas mais adequadas, por permitir a justaposição de tecnologias de ponta com os conhecimentos sobre a natureza disponíveis pelas comunidades locais, respondendo às necessidades locais de sobrevivência e melhoria da qualidade de vida, ao mesmo tempo em que incrementa o uso sustentado dos recursos naturais.

Antes tratado sob a lógica da derruba-e-queima, o manejo da capoeira, hoje, tem a possibilidade de incorporar uma nova tecnologia capaz de triturar essas vegetações, fertilizar o solo com os resíduos orgânicos da vegetação, impedir a emissão de carbono e aumentar a produtividade da propriedade, técnica esta preconizada pelo Projeto Tipitamba. Os resultados atuais mostram que nesse sistema sem queima as vantagens evidenciadas dizem respeito a um melhor balanço de nutrientes, qualidade do solo, melhor conservação da água e regulação térmica do solo, intensificação do sistema de produção, mudança do calendário agrícola, redução

\footnotetext{
* O artigo corresponde ao capítulo dois da Tese de Doutorado em Agroecossistemas Sustentáveis da Amazônia, cuja proposta é desenvolver um Modelo de gestão, baseado em aliança estratégica multiinstitucional para implementar o sistema de trituração da capoeira sem queima em nível da agricultura familiar no nordeste paraense.

${ }^{1}$ Bacharel em Comunicação Social - Jornalismo e Publicidade e Propaganda (UFPA), mestra em Comunicação Rural e Administração Rural (UFRPE), doutoranda em Ciências Agrárias - Agroecossistemas da Amazônia (UFRA/Embrapa). Endereço: WE 22 - casa 281 - Conjunto Cidade Nova II - Bairro Coqueiro - Ananindeua, Pará. CEP: 67130-500. Fone: (91)32730335, cel. (91) 88229750, e-mail: cenisamp@zipmail.com.br ou lindasamp@zipmail.com.br.

${ }^{2}$ Engenheiro agrônomo, doutor em Agricultura Tropical, pesquisador da Embrapa Amazônia Oriental, Coordenador do Projeto Tipitamba, professor da Universidade Federal Rural da Amazônia e orientador da tese. Fones: (91)32766539, cel. (91)81459249, e-mail: <okato@cpatu.embrapa.br>.

${ }^{3}$ Bacharel em Administração (UFPA), mestre em Administração (UFSC) e doutor em Engenharia de Produção (UFSC). Professor e pesquisador do Curso de Mestrado em Economia e graduação em Administração da Universidade da Amazônia (UNAMA) e do curso de Administração da Faculdade do Pará (FAP) e co-orientador da tese. Av. Pedro Miranda, 624 - Ed. Pirâmide, apart ${ }^{0} 901$ - Pedreira, Belém, Pará, CEP. 66085-005. Fones: (91)9913-0907 e 3233-1757, e-mail: < $\underline{\text { danielnssilva@yahoo.com.br>. }}$
} 
na incidência de plantas espontâneas e à oferta de serviços ambientais, como, por exemplo, o seqüestro de carbono.

Palavras-chave: uso da terra; sistema sustentável florestal; agroecossistemas; qualidade de vida.

\begin{abstract}
The crisis related to the climatic changes and the global heating, in this beginning of century, is a problem that call for actions capable to answer to the inquietudes of the society. Amongst other actions, what he has been complained is in the form of management and exploitation of the natural resources. The generation of technology of the cut and triturating of the coop without burning points the ways capable to guarantee the security of the local communities, hindering deterioration them ecosystems and the degradation human being. In the case of the Amazon, mainly, it is configured more in one of the forms adjusted by allowing the juxtaposition of technologies of tip with the knowledge on the nature available for the local communities, answering to the local necessities of survival and improvement of the quality of life, at the same time where it develops the supported use of the natural resources. Before treated under the logic to knock down-and-it burns, the handling of the coop, today, has the possibility to incorporate a new technology capable to triturate these vegetations, to fertilizer the ground with the organic residues of the vegetation, to hinder the carbon emission and to increase the productivity of the property, technique this praised by the Tipitamba Project. The current results show that, in this system without burning, the evidenced advantages say respect to one better rocking of nutrients, quality of the ground, more good conservation of the water and thermal regulation of the ground, intensification of the production system, change of the agricultural calendar, reduction in the incidence of spontaneous plants and it offers of ambient services, as, for example, the carbon kidnapping.
\end{abstract}

Key words: use of the land; forest sustainable system; agroecossistemas; quality of life

\title{
Introdução
}

O sistema de corte e trituração se caracteriza como uma alternativa de uso da terra sem precisar queimar. Trata-se de uma iniciativa de pesquisa e desenvolvimento posta em prática pela Embrapa e por universidades alemãs, através do Projeto SHIFT - Capoeira, hoje denominado Tipitamba. O Projeto Tipitamba compõe o Programa Nacional de Sistema de Produção Florestal e Agroflorestal da Embrapa e está inserido no projeto “Aperfeiçoamento e validação de tecnologias de manejo de capoeiras que visa ao uso sustentado da capoeira como vegetação de pousio na agricultura da Amazônia Oriental”. Dadas as relevantes contribuições que o sistema proporciona ao homem, pela melhora da capacidade produtiva do solo, melhor uso da terra e preservação do meio ambiente - conseqüentemente, à sustentabilidade do sistema de produção -, este artigo pretende evidenciar os avanços da técnica de derruba-sem-queima, no sentido de sua implementação e disseminação da prática no âmbito da agricultura familiar no Nordeste paraense.

O objetivo é não apenas compreender a importância da técnica de corte e trituração da capoeira no âmbito da agricultura familiar na região do Nordeste paraense, mas também como uma alternativa de uso da terra capaz de evitar a degradação do meio ambiente. Nesse sentido, busca-se evidenciar as contribuições que esse sistema de manejo da capoeira sem o uso do fogo proporciona aos agricultores familiares com vistas à sustentabilidade dos recursos naturais amazônicos. O artigo está organizado em seis seções. Num primeiro momento, é ressaltada a importância dos recursos naturais da Amazônia, num confronto com as questões 
ambientais, e o porquê da agricultura sem queima. E seguida, é abordada a trituração da capoeira no contexto agroecosistemy, para em seguida serem mostradas as vantagens do sistema de corte e trituração da capoeira. Os resultados sugerem propostas estratégicas, com vistas à adoção da tecnologia pelos agricultores. Seguem-se as considerações finais e as referências.

\section{Os recursos naturais da Amazônia e a importância da agricultura sem queima}

Há duas décadas, instituições governamentais e não-governamentais vêm atuando nas áreas social e ambiental com vistas à preservação dos recursos naturais ameaçados pelo uso indiscriminado do fogo. Não só os cientistas, mas também governo e sociedade, em geral, têm se mobilizado nesse sentido. A ordem global é que o homem assuma o compromisso de desenvolver ações no sentido da sustentabilidade dos recursos naturais, o que é um dos objetivos do milênio.

A preservação ambiental, o respeito ao meio ambiente e a utilização limpa dos recursos disponíveis significam pensar na qualidade de vida atual e das gerações futuras. Em 2003, diversos países, inclusive o Brasil, firmaram um acordo assumindo a responsabilidade pelo planeta. Esse compromisso internacional consiste no desenvolvimento de ações concretas a serem executados pelos governos, de modo a mobilizar a sociedade, cujos objetivos devem ser atingidos até 2015.

No sentido de montar um Painel Intergovernamental sobre Mudanças do Clima, (IPCC), em 2005, a Organização das Nações Unidas (ONU) reuniu cerca de 2.500 cientistas de 130 países com representantes do mundo todo. Os resultados desse painel apontam o homem como um dos vilões do aquecimento global, confirmando, inclusive, que o grande responsável pelo efeito estufa que está elevando a temperatura da Terra é o aumento da emissão de gases principalmente, o dióxido de carbono $\left(\mathrm{CO}_{2}\right)$ - liberado pela queima de combustíveis fósseis, como o petróleo e o carvão, e por incêndios nas florestas; ações essas, todas, praticadas pelo ser humano.

Sabe-se que as queimadas afetam a atmosfera ao aumentar a quantidade de gás carbônico. Da mesma forma, sabe-se que o fogo, apesar da sua importância na vida do agricultor - é considerado uma das mais antigas tecnologias incorporadas aos sistemas de produção, além de rápida, barata e eficaz - é tida, nesse cenário, como um dos maiores problemas no mundo, devido aos seus efeitos negativos no meio ambiente. Portanto, o problema das queimadas, que vem provocando mudanças climáticas e o aquecimento global, entre tantos outros fatores de degradação do meio ambiente, requer ações inter e multidisciplinares, haja vista que não se trata apenas de uma questão ambiental, mas também social, econômica, política, ética e cultural.

A geração de tecnologia voltada à sustentabilidade dos recursos naturais torna-se, fundamentalmente, relevante por apontar caminhos a serem seguidos pelo homem, de certa forma, capazes de garantir a segurança das comunidades locais, regionais, nacionais e globais, impedindo a deterioração dos ecossistemas e a própria degradação humana. Contudo, isso não é suficiente. São necessárias ações estratégicas adotadas de forma conjunta (ou multiinstitucional) que permitam que os resultados não mais sejam lentos e reticentes, mas sim imediatamente postos em prática pelo homem.

\section{A Amazônia como fonte de recursos}

A Amazônia, denominada "pulmão do mundo", tornou-se uma referência global nas últimas décadas. A ECO-92 foi um evento que provocou a busca de alternativas capazes de minimizar os danos causados pelo homem à natureza. A partir de então, muitas tem sido as instituições que se identificam como responsáveis pela preservação. Entre outras, a Empresa 
Brasileira de Pesquisa Agropecuária (Embrapa), cuja missão passou a ter como foco o conhecimento, as tecnologias, os serviços e os produtos em atendimento aos objetivos de gestão e uso da terra (visando subsidiar o desenvolvimento sustentável da agricultura familiar) e a agricultura empresarial ou de larga escala (visando subsidiar o desenvolvimento da pecuária, dos cultivos industriais e do reflorestamento). Entende-se, porém, que a geração de tecnologia, no contexto da missão da Embrapa, aliada aos conhecimentos sobre a natureza disponíveis pelas comunidades locais, configuram uma importante alternativa capaz de responder, em parte, aos anseios da sociedade. A agricultura sustentável é um conceito difícil de definir e, muito mais ainda, de ser posto em prática. Entretanto, o essencial é que cada um compreenda a importância do corte e trituração sem queima (ou agricultura sustentável) para a segurança alimentar, bem como a importância desta para a estabilidade econômica e social dos agricultores familiares (GUIMARÃES FILHO, 1998).

Na perspectiva da agricultura familiar, foi criado o protótipo de uma máquina de trituração, denominada Tritucap, que vinha sendo desenvolvida pela equipe do Projeto SHIFT na Alemanha. Enquanto as pesquisas se desenvolviam na busca de um protótipo operacional, as experiências foram sendo realizadas com uma máquina de trituração de florestas já existente em caráter comercial na Alemanha. Essa máquina, Ahwi FM600, importada daquele país, juntamente com um trator John Deere 7710 de 166 Hp, possuía as especificações adequadas de potência para tracioná-la. Do ponto de vista do equipamento de trituração, os estudos de custo foram realizados, fornecendo informações preliminares sobre os custos econômicos privados da trituração das capoeiras, a partir do pacote proposto, como mostra a figura 1.

Figura 1

Modelo de trituradeira usada para preparo de área via corte - mulch: Tritucap - FM 600 da AHWI

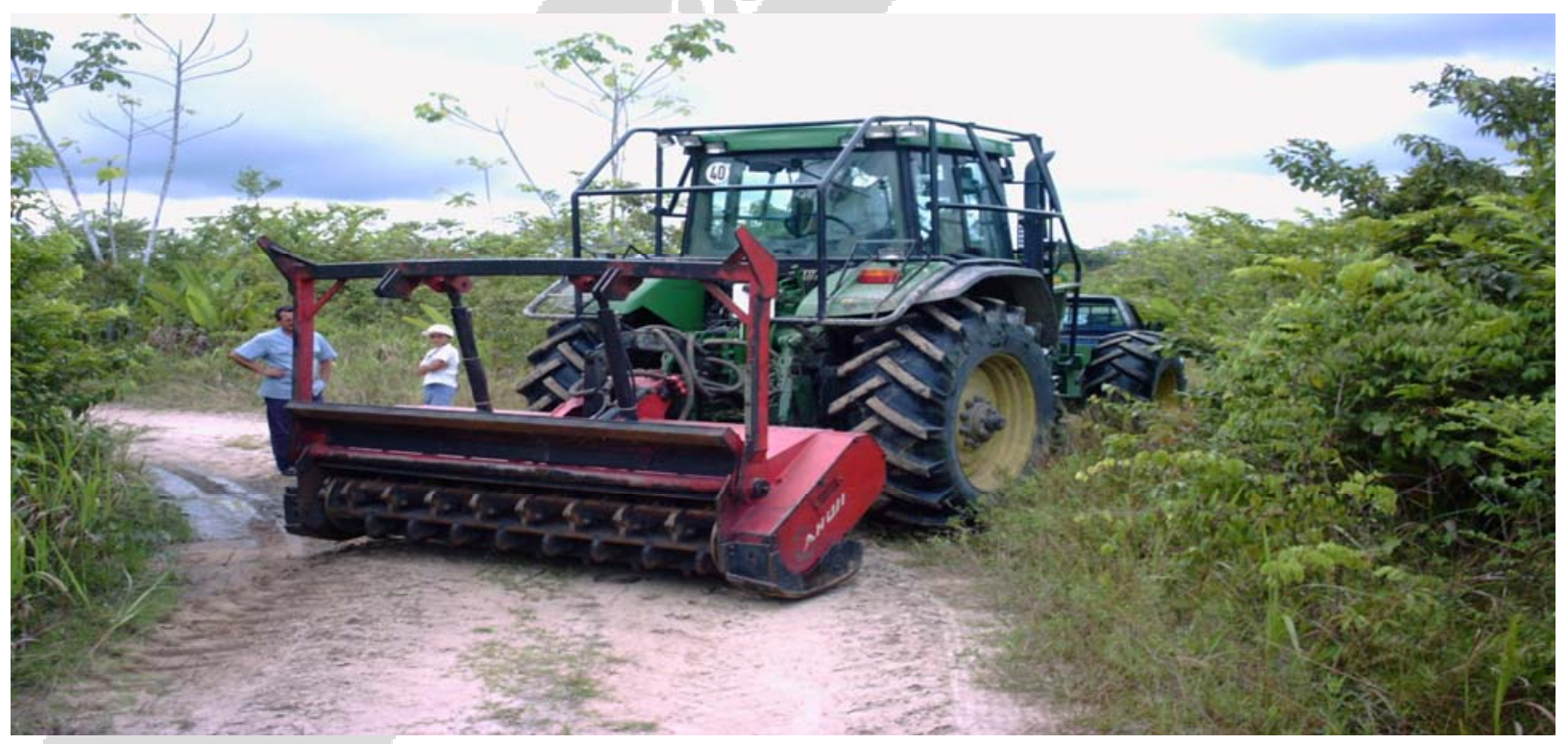

Fonte: SÁ, T.D. de A. Relatório Técnico CNPq 4. Projeto Tipitamba, ENV.25, 2002, p.12.

A Embrapa Amazônia Oriental, juntamente com o Centro de Pesquisa para Desenvolvimento ZEF Bonn e a Universidade de Göttingen, da Alemanha, tendo como instrumentalização o Projeto SHIFT-capoeira, consolidou a tecnologia Tritucap, em uso nas comunidades rurais do nordeste paraense há 10 anos. Caracterizado, neste trabalho, como resultado da metodologia de uso da terra no contexto agroecossistêmico da Amazônia, é uma 
prática adotada pelos agricultores familiares de alguns municípios do nordeste paraense no reaproveitamento da capoeira, em pousio, com idade até oito anos.

\section{A trituração como uma metodologia de uso da terra}

A trituração da capoeira preconizada pelo Tipitamba, que hoje significa uma resposta positiva do projeto SHIFT-capoeira, integra o Programa Nacional de Sistema de Produção Florestal e Agroflorestal da Embrapa e se insere no projeto "Aperfeiçoamento e validação de tecnologias de manejo de capoeiras que visa ao uso sustentado da terra na Amazônia Oriental”. Trata-se de uma iniciativa conjunta ("guarda-chuva”) que inclui mais cinco subprojetos: aperfeiçoamento e teste de equipamentos visando ao preparo de área sem queima, técnicas de preparo de área sem o uso do fogo, melhoramento das capoeiras com árvores leguminosas de rápido crescimento, integração da pecuária bovina no ciclo da capoeira e avaliação socioeconômica e valoração da tecnologia sem queima e capoeira melhorada, como pode ser verificado no quadro 1.

\section{Quadro 1}

Passos da iniciativa conjunta - "guarda-chuva"- Tipitamba.

\begin{tabular}{|c|c|c|c|c|c|c|c|c|c|c|c|c|c|c|c|c|c|c|}
\hline $\begin{array}{l}\text { Períodos } \\
\text { SHIFT/TIPITAMBA } \\
(1991-2007)\end{array}$ & $\begin{array}{l}1 \\
9 \\
9 \\
1\end{array}$ & $\begin{array}{l}1 \\
9 \\
9 \\
2\end{array}$ & $\begin{array}{l}1 \\
9 \\
9 \\
3\end{array}$ & $\begin{array}{l}1 \\
9 \\
9 \\
4\end{array}$ & $\begin{array}{l}1 \\
9 \\
9 \\
5\end{array}$ & $\begin{array}{l}1 \\
9 \\
9 \\
6\end{array}$ & $\begin{array}{l}1 \\
9 \\
9 \\
7\end{array}$ & $\begin{array}{l}1 \\
9 \\
9 \\
8\end{array}$ & $\begin{array}{l}1 \\
9 \\
9 \\
9\end{array}$ & $\begin{array}{l}2 \\
0 \\
0 \\
0\end{array}$ & $\begin{array}{l}2 \\
0 \\
0 \\
1\end{array}$ & $\begin{array}{l}2 \\
0 \\
0 \\
2\end{array}$ & $\begin{array}{l}2 \\
0 \\
0 \\
3\end{array}$ & $\begin{array}{l}2 \\
0 \\
0 \\
4\end{array}$ & $T$ & $\begin{array}{l}2 \\
0 \\
0 \\
5\end{array}$ & $\begin{array}{l}2 \\
0 \\
0 \\
6\end{array}$ & $\begin{array}{l}2 \\
0 \\
0 \\
7\end{array}$ \\
\hline Propostas recentes & & & & & & & & & a & 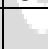 & $x$ & $x$ & $x$ & $x$ & $P$ & & & \\
\hline Embrapa-082000-34 & & & & & & & & & 14 & $x$ & $x$ & $x$ & $x$ & $x$ & & & & \\
\hline Embrapa-0897014 & & & & & & 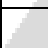 & & $x$ & $x$ & & & & & & $I$ & & & \\
\hline Embrapa-2 & & & & $x$ & $x$ & $x$ & $X$ & & 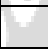 & & P & & & & & & & \\
\hline Embrapa-1 & $x$ & $x$ & $x$ & & & & & $\mathrm{st}$ & & & 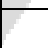 & & & & $T$ & & & \\
\hline PPG-7 & & & & & & & 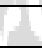 & ${ }_{2}$ & & $x$ & $x$ & $x$ & $x$ & & & & & \\
\hline FUNTEC2 & & & & & & & & 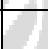 & & 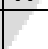 & $x$ & $x$ & & & $A$ & & & \\
\hline FUNTEC1 & & & & & & & 7 & 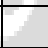 & & $x$ & $x$ & & & & & & & \\
\hline SHIFT-Pecuária & & & & & 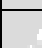 & l & & & $x$ & $x$ & $x$ & & & & $M$ & & & \\
\hline SHIFT-Ag.Familiar & & & & & $x$ & $x$ & $\mathrm{X}$ & $x$ & $x$ & $x$ & & $x$ & $x$ & $x$ & & & & \\
\hline SHIFT-Capoeira & $x$ & $x$ & $x$ & $x$ & $x$ & $x$ & $\mathbf{x}$ & $x$ & $x$ & $x$ & $x$ & $x$ & $x$ & $x$ & & & & \\
\hline $\begin{array}{l}\text { TIPITAMBA/ } \\
\text { PDA/PADEQ- } \\
\text { Raízes da Terra }\end{array}$ & & & & & & & & & & & & & & & & $x$ & $x$ & $x$ \\
\hline
\end{tabular}

Fonte: EMBRAPA/CPATU. Produzir sem queimar - Tipitamba. Belém-Pará, 2001. Folder.

A agricultura de derruba-e-queima pode ser caracterizada como um sistema de uso da terra que utiliza o fogo na vegetação natural para o cultivo agrícola. Essa prática ocorre durante um ou dois anos, seguindo-se um período de pousio. Nessa fase, a vegetação secundária (capoeira) se refaz por meio de rebrotas de tocos, raízes e sementes, principalmente, aquelas que sobrevivem ao corte e à queimada.

Os estudos realizados nesse âmbito mostram que as taxas de rotação exigem períodos de pousio longos, de modo que a nova vegetação recomposta possa contar, pelo menos parcialmente, com a diversidade florística, a ciclagem de água e nutrientes (HÖLSCHER et al, 1997a, 1997b; SOMMER 2004), proporcionando, ao mesmo tempo, o acúmulo de carbono e nutrientes na sua biomassa (DENICH, 1991; DENICH; KANASHIRO; VLEK, 1999; TIPPMANN et al, 2000).

Portanto, a estabilidade de produção, segundo esses pesquisadores citados, é resultante dos efeitos desse sistema rotacional, baseada no uso do fogo que disponibiliza nutrientes 
acumulados na biomassa durante o pousio, no controle de invasoras resultante da recomposição florística e na proteção do solo pela rede de raízes da capoeira (DENICH et al, 2004).

As pesquisas de Metzger (2000), KATO et al,(2006 a) e Kato et al (2006b) mostram que o decrescimento do período de pousio, decorrente da crescente pressão populacional, e a necessidade de produção de alimentos diminuem os efeitos benéficos do período, pois as repetidas queimadas representam uma contínua perda de nutrientes minerais e uma maior exposição do solo, juntamente com a retirada dos resíduos da serrapilheira e o aumento da mineralização da matéria orgânica.

Por outro lado, no sentido de enfatizar a importância da agricultura familiar nesse contexto, Kato et al (2006 b) acrescentam que a agricultura familiar, na prática das queimadas para o cultivo na região, responde por $70 \%$ dos alimentos básicos da população brasileira. Cerca de 600 mil famílias agricultoras na Amazônia são consideradas praticantes do tradicional sistema de derruba-e-queima.

Essa realidade apontada pelo pesquisador leva à conclusão de que, apesar dos avanços das pesquisas mostrando os graves efeitos das queimadas, ainda é enorme o índice do desmatamento e do uso do fogo na região, pela própria necessidade de produzir alimentos. Isso vem, direta ou indiretamente, de forma involuntária, contribuir para a emissão de gases para a atmosfera e para o aquecimento global da Terra, aumentando os riscos de incêndios florestais (DIAZ et al, 2003).

Com base nos estudos que evidenciam o balanço negativo do sistema de derruba-equeima - provocado, principalmente, pelas perdas de nutrientes durante a queima da vegetação no preparo de área para o plantio - Sommer (2000) e Hölscher et al (1997a) consideram que foi dado um impulso à melhora do sistema de preparo de área sem a utilização do fogo (ver tabela $1)$.

\section{Tabela 1}

Balanço de nutrientes nos sistemas de derruba-e-queima e corte de trituração

\begin{tabular}{|c|c|c|c|c|c|c|}
\hline Preparo de área & $\mathbf{N}$ & $\mathbf{P}$ & $\mathbf{K}$ & Ca & Mg & $\mathbf{S}$ \\
\hline (Fontes de ganhos e perdas de nutrientes) & ---- & --- & --- & Kg/ha & $\begin{array}{ll}----1 \\
\end{array}$ & --- \\
\hline \multicolumn{7}{|l|}{ Derruba-e-queima } \\
\hline Deposição atmosférica & $26^{1}$ & 4 & 12 & 30 & 15 & 22 \\
\hline Adubação & 70 & 48 & 66 & 31 & - & - \\
\hline Perdas de queima & -246 & -8 & -58 & -151 & -29 & -35 \\
\hline Perdas por lixiviação & -16 & -1 & -11 & -48 & -9 & -5 \\
\hline Perdas pela colheita & -127 & -22 & -78 & -16 & -14 & -7 \\
\hline Balanço & -293 & 21 & -69 & -154 & -37 & -25 \\
\hline \multicolumn{7}{|l|}{ Corte e trituração } \\
\hline Deposição atmosférica & $26^{1}$ & 4 & 12 & 30 & 15 & 22 \\
\hline Adubação & 70 & 48 & 66 & 31 & - & - \\
\hline Perdas por lixiviação & -10 & -1 & -3 & -25 & -6 & -13 \\
\hline Perdas pela colheita & -112 & -22 & -8 & 22 & -3 & 2 \\
\hline Balanço & -26 & 29 & -8 & 22 & -3 & 2 \\
\hline Ganhos através do corte e trituração & 267 & 8 & 61 & 176 & 34 & 27 \\
\hline
\end{tabular}

Fonte: adaptado de Denich et al (apud KATO et al, 2006 b).

A proposta para preparo da área sem o uso do fogo, inicialmente, consistia no trabalho manual. Porém, essa prática demandou grande mão-de-obra, que somente poderia ser viabilizada com maior facilidade quando trabalhada na forma de mutirão.

Diante desse problema, na tentativa de reduzir o trabalho manual, foram identificadas alternativas que facilitassem essa operação. Foram criadas as chamadas ensiladeiras de forragens. Essa alternativa, apesar dos esforços no sentido de melhorar o processo e minimizar a 
quantidade de mão-de-obra, acabou aumentando ainda mais o trabalho (DENICH et al, 2004). Portanto, foi considerado sem resultados satisfatórios.

Essa problemática impulsionou a Embrapa Amazônia Oriental, juntamente com a Universidade de Göttingen, a construir um protótipo de triturador de capoeira motomecanizado que recebeu o nome de Tritucap. O equipamento é acoplado a um trator de rodas e realiza a derruba da vegetação triturando a biomassa, enquanto distribui sobre o terreno na forma de cobertura morta (mulch), numa única operação (BLOCH, 2004). O plantio, realizado na forma direta, é denominado "plantio direto na capoeira” (KATO et al, 2004).

Entretanto, para se obter uma produção satisfatória, essa fase da regeneração da biomassa ainda exige que seja adicionada certa quantidade de fertilizantes (KATO et al, 1999). A adubação complementar nas áreas preparadas sem queima, na opinião de Kato (2004), devido à imobilização dos nutrientes na fase inicial, pode compensar o efeito negativo quando comparado com a produção nas áreas queimadas, garantida pela adição de nutrientes provenientes das cinzas. O autor ressalta, por exemplo, que a produção de arroz no sistema de corte e trituração, sem adubação complementar, aumentou de 0,9 ton $/ \mathrm{ha}^{-1}$ para 1,5 ton $/ \mathrm{ha}^{-1}$ no segundo cultivo consecutivo, semelhante à produção nas áreas queimadas no primeiro ano de cultivo (safra 1995/1996). Os resultados também evidenciaram melhor estabilidade de produção de raízes frescas de mandioca no sistema sem queima, ao longo dos anos. O sistema de corte e trituração sem queima foi avaliado, também, em relação aos efeitos do nitrogênio, fósforo e potássio na produção de milho (BÜNEMMAM, 1988), constatando-se que o fósforo é o elemento que mais limita a produção.

Esses resultados foram confirmados por Kato et al (2004) em experimento que avaliou os níveis de aplicação de fósforo, nitrogênio e potássio com milho. Ficou provado que, à medida que aumentaram as doses de potássio, ocorreu aumento na produção de grãos de milho, sendo a maior resposta observada com a aplicação de $30 \mathrm{~kg} / \mathrm{ha}^{-1}$ de $\mathrm{P}_{2} \mathrm{O}_{2}$. Sem a aplicação de potássio, a cultura do milho não se desenvolveu. Testado no cultivo de maracujá, os resultados confirmam que as melhores produções de frutos de maracujá foram alcançadas a partir do sistema de corte e trituração $\left(20,7\right.$ ton$\left./ \mathrm{ha}^{-1}\right)$ e de aração e gradagem $\left(21,9\right.$ ton $\left./ \mathrm{ha}^{-1}\right)$. A produção de maracujá pelo sistema de derruba-e-queima foi a que apresentou menor desempenho $\left(14,8\right.$ ton $\left./ \mathrm{ha}^{-1}\right)$. Embora a produção nas áreas de corte e trituração tenha sido igual à aração e gradagem, as plantas na área de trituração apresentaram melhor desenvolvimento, sofreram menor stress hídrico na época mais seca, menor incidência de plantas invasoras e apresentaram maior capacidade de regeneração da capoeira.

No que diz respeito às pastagens, os estudos de Camarão et al (2002) provam que a oferta de forragem de capim-braquiarão associado com quicuio da Amazônia no sistema de trituração é maior do que no sistema com queima, além de ser observada menor incidência de plantas espontâneas na pastagem cultivada, em áreas sem o uso do fogo.

\section{Vantagens da derruba sem queima ou corte e trituração}

Os estudos de Sommer et al (2004) demonstram que, ao evitar perdas de nutrientes com a queima da biomassa aérea, a derruba sem queima contribui para um balanço positivo de nutrientes. Assim, enquanto a agricultura de corte e queima ocasiona grande perda de fertilidade dos solos, o sistema de corte e trituração proporciona a recuperação gradual desses solos por apresentar constantes ofertas de nutrientes e carbono. As raízes da vegetação secundária também são outro ponto positivo, uma vez que desempenham papel relevante na ciclagem de nutrientes lixiviados no perfil do solo, porque reciclam os nutrientes das camadas profundas do solo para a superfície SOMMER, 2004; SOMMER et al, 2004; WICKEL, 2004).

No que se refere à qualidade do solo, toda biomassa aérea da vegetação secundária no sistema de corte e trituração é fonte de matéria orgânica para o sistema. A quantidade dessa 
biomassa varia de acordo com sua idade, com o sistema de uso da terra e com a intensificação desse uso, podendo variar, segundo Kato et al (2006b), de 8ton/ha ${ }^{-1}$ (capoeira de um ano) a 90ton/ha ${ }^{-1}$ (capoeira de 10 anos). A qualidade do solo é uma das maiores vantagens assinaladas por Kato et al (2006b), devido aos maiores teores de carbono orgânico no solo, principalmente, na camada superficial, quando o sistema de corte e trituração é utilizado no preparo de área. As pesquisas permitiram a identificação de maiores concentrações de glomalina - glicoproteína produzida pelos FMA no solo da rizosfera da área triturada e da área de capoeira -, que tem grande influência na cimentação dos agregados, favorecendo, assim, maior estruturação do solo. A oferta de serviços ambientais, portanto, é da maior relevância nessa ambiência do Tipitamba, como, por exemplo, o seqüestro de carbono.

De acordo com Hölscher et al (1997a), durante a queima da vegetação perde-se $98 \%$ do carbono estocado na biomassa. A contribuição para o seqüestro de carbono pelos cultivos agrícolas durante a fase agrícola do sistema é de 2,1 ton/ha ${ }^{-1}$ de carbono pela cultura do milho (quatro meses), de 1,6ton/ha ${ }^{-1}$ pelo caupi, de 2,6 a 5,6ton/ha ${ }^{-1}$ pela mandioca (1-1,5 anos), de 2,6ton/ha ${ }^{-1}$ pelo maracujá (um ano) e de 5,3 ton/ha- ${ }^{1}$ pela pimenta do reino com 2,5 anos de idade (DENICH; KANASHIRO; VLEK, 1999).

Ainda de acordo com Denich, Kanashiro e Vlek (1999), as vegetações secundárias em pousio em propriedades agrícolas e em nível de paisagem são capazes de acumular carbono acima e abaixo do solo. As capoeiras melhoradas com o plantio de leguminosas de rápido crescimento também acumulam carbono, e as capoeiras melhoradas com Racosperma mangium são as que apresentaram maior seqüestro de carbono (ver tabela 2).

Tabela 2

Estoque de carbono na biomassa aérea de capoeiras naturais e melhoradas

\begin{tabular}{|l|c|c|}
\hline \multicolumn{1}{|c|}{ Capoeira } & Idade (meses) & Carbono (t ha \\
\hline Capoeira natural & 30 & 9,5 \\
\hline Capoeira melhorada & & \\
\hline Acacia auriculiformes & 21 & 18,9 \\
\hline Acacia angustissima & 30 & 13,9 \\
\hline Clitoria racemosa & 30 & 10,9 \\
\hline Inga edulis & 30 & 12,3 \\
\hline Racosperma mangiun & 30 & 23,6 \\
\hline
\end{tabular}

Fonte: adaptado de Brienza Júnior (1999) e Denich, Kanashiro e Vlek (1999).

A conservação da biodiversidade, a dinâmica de água e nutrientes (manutenção das taxas de recarga dos estoques de água subterrânea, manutenção das vazões de igarapés e rios e redução de impactos nos sistemas aquáticos ocasionados pela lixiviação de nutrientes) são contribuições já provadas pela prática da trituração de corte sem queima, preconizadas pelo projeto Tipitamba (WICKEL, 2004).

\section{Aspectos metodológicos do estudo}

Para os objetivos do estudo, foi realizado um levantamento bibliográfico, através da literatura sobre as origens, evolução e estágio atual do Tipitamba. Foi um estudo de caso, onde os dados são analisados indutivamente, sendo ao mesmo tempo descritivo, porque o processo e seu significado passam a ser os focos principais de abordagem. A pesquisa é do tipo explicativa porque identifica o sistema de corte e trituração sem o uso do fogo como o fator que determina ou contribui para não agravar os fenômenos relacionados às mudanças climáticas e ao aquecimento global, aprofundando, assim, o conhecimento da realidade. 


\section{Coleta de dados}

Trata-se de uma pesquisa documental onde constam todas as informações sobre o Tipitamba, como relatórios técnicos, publicações e documentos. Dentre outros, um estudo realizado por quatro grupos de trabalho (dois do Núcleo de Altos Estudos Amazônicos da Universidade Federal do Pará - Naea/UFPA, um da Universidade de Bonn, Alemanha, e outro da Embrapa Pará), os quais analisam a viabilidade socioeconômica da trituração motomecanizada numa perspectiva de inovação e difusão tecnológica para a sustentabilidade da agricultura familiar na Amazônia (COSTA,F.A; HURTIENNE, T.; e KAWAGE, C., 2006). O grupo elegeu Igarapé-Açu como lugar privilegiado da pesquisa laboratorial, ampliando a compreensão para as microrregiões Bragantina e Guajarina, da mesorregião do Nordeste paraense. A agricultura familiar serviu como principal referência estrutural das pesquisas.

Block (2006) se preocupou com o tempo gasto para triturar uma determinada área de acordo com o seu tamanho, tipo da capoeira, solo, culturas implantadas e o tempo do deslocamento entre propriedades. Costa (2006) procura situar as capoeiras do ponto de vista econômico como partes de tecnologias concorrentes com trajetórias determinadas, as quais resguardam condições de path dependency a determinar a forma como os novos conhecimentos tecnológicos são absorvidos, inclusive, aqueles para os quais se voltam as técnicas em estudo.

$\mathrm{Na}$ perspectiva do produtor de bens de capital, Costa (2006) ressalta que as chances crescem na medida em que tais conhecimentos permitem a produção de um bem tecnológico novo que substitui uma técnica preexistente na produção de um ou de outro elenco de produtos com custo menor. $\mathrm{O}$ pesquisador acrescenta, ainda, que tais chances crescem, ademais, com a versatilidade da técnica de manejo em questão, ou seja, na medida em que ela venha a substituir, em condições vantajosas, não apenas uma técnica específica, mas um conjunto de técnicas na produção de um conjunto de produtos. A versatilidade define a escala em que é possível produzir o bem em tela e, assim, co-determina as condições de lucratividade na sua obtenção.

Michelotti (2006, ao tratar dos custos de trituração da capoeira no nordeste paraense, em uma primeira aproximação, chega a estimativas de custo por hora de trituração sob diversas hipóteses de escala. Bevilaqua (2006) - de posse de parâmetros estabelecidos no trabalho de Michelotti (2006) -, não somente apresenta resultados compulsados a partir de aplicações de técnicas em dois municípios paraenses (Concórdia do Pará e Rio Maria), como chama a atenção para a influência da densidade da capoeira na determinação de custos e faz exercícios econométricos de sensibilidade desses valores em relação às variáveis fundamentais.

Figueiredo \& Hurtienne (2006) e Freitas \& Gomes (2006) apresentam resultados das implicações desses custos nas condições de rentabilidade e eficiência reprodutiva dos camponeses, pressuposta clientela preferencial das técnicas de trituração sem queima. Os primeiros, para precisar o papel das capoeiras entre os camponeses estudados e o efeito das novas técnicas; os segundos, para explorar a metodologia DEA (data envelopment analysis), em que avaliam economicamente a eficiência de sistemas agrícolas cultivados com a tecnologia mulch.

Todos os estudos apontam para as barreiras que o custo de operação dos equipamentos trituradores no nível de desenvolvimento atual representa para uma ampla absorção das tecnologias desenvolvidas pelos agricultores familiares e que dependem da obtenção de recursos. Outros estudos procuram ver a possibilidade de uso das tecnologias a partir de questões relacionadas às bases produtivas dos agricultores e a organização social onde se encontram implicações das inovações numa perspectiva de sustentabilidade ambiental, entre outras. Tais estudos indicam necessidades institucionais compatíveis com as exigências correlatas. Fatores determinantes em relação a isso é o ambiente institucional, o grau de desenvolvimento e consistência das redes sociais presentes nas regiões estudadas. 
Finalmente, Rodrigues et al (2004) avaliaram a diversidade e a estrutura vertical da vegetação secundária em pousio, em áreas trituradas motomecanizada, não sendo encontradas diferenças no padrão de distribuição dos indivíduos e na diversidade das espécies quando comparado com a capoeira inicial. Na opinião dos pesquisadores citados, essa é a razão para os produtores aterem-se na agricultura de derruba e queima para limpeza e preparo do solo para plantio. Entretanto, essas mesmas pesquisas sustentam a importância da trituração, a partir das significativas contribuições apresentadas nas operações de manejo da capoeira e na produção de cobertura morta, bem como na recuperação e fixação de nutrientes, o que tornam a trituração sem o queima, preconizado pelo Projeto Tipitamba, altamente competitiva em relação ao sistema de cultivo tradicional.

\section{Resultados}

A avaliação feita com foco na adesão do sistema de corte e trituração pelos agricultores relata que em 2000, essa adesão foi de, apenas, seis agricultores. Em seguida, esse número subiu para 21 em cinco comunidades nos municípios de Igarapé-Açu e Marapanim (PA). Em 2007, o projeto contava com 46 agricultores. Mesmo tendo sido ampliado para outros municípios, como no Pólo Rio Capim, do Programa Proambiente - composto pelos municípios de Concórdia do Pará, Mãe do Rio, Irituia e São Domingos do Capim -, há uma adesão de 33 agricultores familiares, enquanto em Barcarena, com o apoio da Albrás, são 20. Deve ser ainda ressaltado que a adaptação e a validação do sistema de corte estão sendo expandidas para os estados do Acre, Amapá, Amazonas, Rondônia, Roraima e Maranhão, numa parceria com as unidades locais da Embrapa. Porém, por falta de recursos, a prática ainda é bastante tímida.

O projeto avançou bastante e há um interesse significativo pela implementação da trituração motomecanizada nas comunidades. Fica bastante claro que o problema da adoção do sistema de corte e trituração no âmbito da agricultura familiar não é apenas cultural, mas trata-se de uma questão séria e complexa decorrente da falta de recursos e da inexistência de capacidade de gestão por parte dos agricultores. Ficou evidenciada a falta de credibilidade nas instituições públicas. Os agricultores lamentam não haver um gerenciamento forte na comunidade.

\section{Conclusão}

O estudo conclui que o sistema de corte e trituração deve ser ampliado no âmbito da agricultura familiar, não mais restrito à Igarapé-Açu, mas para todo o nordeste paraense. Sugerese que, devido aos custos elevados das máquinas, sejam estabelecidos arranjos sociais entre os produtores, para favorecer o uso coletivo compartilhado de recursos e equipamentos. Pela falta de valorização, por parte do governo, da capoeira como um importante componente do sistema, recomenda-se, também, atenção especial aos agricultores familiares por parte das políticas de desenvolvimento.

Finalmente, deve ser ressaltado que uma avaliação local em nível de comunidade poderia permitir o entendimento de outras vantagens, não propriamente no âmbito das propriedades rurais, apenas (sejam vantagens sociais, econômicas ou ambientais), que pudessem compensar os ampliados recursos demandados pela agricultura sem queima.

\section{Referências}

BEVILAQUA, L. Custo de trituração da tecnologia de cobertura morta no Nordeste paraense: experiência do Projeto Shift Capoeira. In: COSTA, F. A.; HURTIENNE .T.; KAHWAGE, C. (Org.). Inovação e difusão tecnológica para sustentabilidade da agricultura familiar na Amazônia: resultados e implicações do Projeto SHIFT Socioeconomia. Belém: UFPA/Naea, 2006. 278p. 
BLOCK, A. Göttingen Mähhäcksler Tritucap, und Forstmulcher - nicht brennend Flächenvorbereitung am Beispiel der Zona Bragantina, Nord- Ost- Amazonien, Brasilien. In: COSTA, F. de A.; HURTIENNE, T.; KAWAGE, C. Inovações e difusão tecnológica para sustentabilidade da agricultura familiar na Amazônia. Resultados e implicações do projeto SHIFT Socioeconomia. Belém: UFPA/Naea, 2006.

BRIENZA JUNIOR, S. Biomass dynamics of fallow vegetation enriched with leguminous trees in the Eastern Amazon of Brazil. Gonttingen Beitrage zur Land -und Forstwirtschaft in den Tropen und Subtropen, Gottingen, 1999. 134p.

BÜNEMMAM, E. Einflub von Mulch und mineralischmen Dunger auf Zea mays und Vigna unguiculata in der Feldumlage wirtshaft Ostamaziniens, Diplomasbeit Georg-AugustUniveeersität Gottingem, 1988.

CAMARÃO, A. P. et al. Disponibilidade de forragem, composição botânica e qualidade da pastagem de capim quicuio-da-amazônia (Brachiaria humidicola) sob três condições. In: REUNIÃO ANUAL DA SOCIEDADE BRASILEIRA DE ZOOTECNIA, 39., 2002, Recife, Anais... Recife: SBZ, 2002. 1 CD-ROM.

COSTA, F. de A. Capoeiras, inovações e tecnologias rurais concorrentes na Amazônia. In: ; HURTIENNE .T.; KAHWAGE, C. (Org.). (Org.). Inovação e difusão tecnológica para sustentabilidade da agricultura familiar na Amazônia: resultados e implicações do Projeto SHIFT Socioeconomia. Belém: UFPA/Naea, 2006. 278p.

; HURTIENNE, T.; KAWAGE,C. (org.) Inovação e difusão tecnológica para sustentabilidade da agricultura familiar na Amazônia: resultados e implicações do Projeto SHIFT Socioeconomia. Belém: UFPA/Naea, 2006. 278p.

DENICH, M. Estudos da importância de uma vegetação secundária nova para o incremento da produtividade do sistema de produção na Amazônia oriental brasileira. Belém: Embrapa/CPATU-GTZ, 1991. 284p.

DENICH, M.; KANASHIRO, M.; VLEK, P. L. G. The potential and dynamics of carbon sequestration in traditional and modified fallow systems of the Eastern Amazon region, Brazil. In: LAL, R.; KIMBLE, J. M.; STEWART, B. A. (Ed.). Global climate change and tropical ecosystems. Boca Raton, CRC: [s.n.], 1999. p.213-229.

DENICH, $M$ et al. Mechanized land preparation in forest-based fallow systems: the experience of eastern Amazonia. Agroforestry Systems, n.61, p.91-106, 2004.

DIAZ, M. de. C. V. et al. O preço oculto do fogo na Amazônia: custos econômicos associados ao uso do fogo. Report of IPAM /IPEA/WHRC, Belém, Pará, Brazil, 43 p. Disponível em: $<$ http/www.ipam.org.br/ publica: publica-papers.php (Novembro, 2003) Acesso em: jan., 2005.

EMBRAPA/CPATU. Produzir sem queimar - Tipitamba. Belém-Pará, 2001. Folder.

FREITAS, A. C. R. de; GOMES, E. G.. Desempenho econômico e eficiência técnica de sistemas agrícolas cultivados com tecnologia mulch na Amazônia Oriental. In: COSTA, F. A.; HURTIENNE .T.; KAHWAGE, C. (Org.). Inovação e difusão tecnológica para 
sustentabilidade da agricultura familiar na Amazônia: resultados e implicações do Projeto SHIFT Socioeconomia. Belém: UFPA/Naea, 2006. 278p.

GUIMARÃES FILHO, C.; SABOURIN, E.; SILVA, P.C.G. da. A pesquisa em agricultura familiar no nordeste semi-árido: uma busca da objetividade. In: SEMINÁRIO A AGRICULTURA FAMILIAR COM BASE DO DESENVOLVIMENTO SUSTENTADO, I., 1997, Jaguariúna, SP. Anais...Jaguariuna :SDR-MA/EMBRAPA-CNPMA, 1998. No prelo.

HÖLSCHER, D. et al. Dynamic of soil chemical parameters in shifting agriculture in the Eastern Amazon agricultural ecosystem. Environ, n.66, p.153-163, 1997a.

Nutrient input-output budget of shift-ing cultivation in Eastern Amazônia. Nutrient Cycl. Agroecosystem, n.47, p.49-57, 1997b.

KATO, O. R. et al. Método de preparo de área sem queima: uma alternativa para agricultura tradicional da Amazônia Oriental. Embrapa Amazônia Oriental, n.13, p.1-3, 1999. Comunicado técnico.

KATO,M.S.A.; SÁ, T.D.de A. \& FIGUEIREDO, R. Plantio direto na capoeira. Ciência e Ambiente, 29:99-111, 2000. In: Sistemas Agroflorestais: bases científicas para o desenvolvimento sustentável. Campos Goytacazes, RJ: Universidade Estadual do Norte Fluminense Darcy Ribeiro, 2006b, 365p.

Uso de agroflorestas no manejo de florestas secundárias. In: SISTEMAS agroflorestais: bases científicas para o desenvolvimento sustentável. Campos dos Goyatacazes, RJ: Universidade Estadual do Norte Fluminense Darcy Ribeiro, 2006b. p.119-138.

KATO, O. R.; SECCO, N. B. Intensificando o cultivo em sistemas agroflorestais sucessionais. In: CONGRESSO BRASILEIRO DE SISTEMAS AGROFLORESTAIS, 5. Ilhéus, Anais... Ilhéus: CBSA, 2004. Documentos, 98), p.111-113.

METZGER, J. P. M. Dinâmica e equilíbrio da paisagem em áreas de agricultura de corte e queima em pousio curto e longo na região bragantina. In: SEMINÁRIO SOBRE MANEJO DA VEGETAÇÃO SECUNDÁRIA PARA A SUSTENTABILIDADE DA AGRICULTURA FAMILIAR DA AMAZÔNIA ORIENTAL, 1998, Belém, Pará, Brasil. Anais...Belém Embrapa Amazônia Oriental, 2000. p. 47-50. (Embrapa Amazônia Oriental, Documentos 69).

MICHELOTTI, F. Análise microeconômica dos impactos e das conseqüências da tecnologia de cobertura morta no âmbito do Projeto SHIFT Capoeira. Relatório final de bolsa de pesquisa.SHIFT -Socioeconomia /Naea. Belém, 2004 In: COSTA, F. A.; HURTIENNE T.; KAHWAGE, C. (Org.). Inovação e difusão tecnológica para sustentabilidade da agricultura familiar na Amazônia: resultados e implicações do Projeto SHIFT Socioeconomia. Belém:UFPA/Naea, 2006a. 278p.

Os custos da trituração da tecnologia de cobertura morta no nordeste paraense: a experiência do projeto SHIFT Capoeira em três municípios. In: COSTA, F. A.; HURTIENNE. T.; KAHWAGE, C. (Org.). Inovação e difusão tecnológica para sustentabilidade da agricultura familiar na Amazônia: resultados e implicações do Projeto SHIFT Socioeconomia. Belém: UFPA/Naea, 2006b. 278p. 
RODRIGUES, M.A.C. de M.; MIRANDA, I. de S. \& KATO, M.S. de A. Estrutura de florestas secundárias originadas após o uso de diferentes trituradores florestais em sistemas agroflorestais seqüenciais no nordeste paraense. In: V Congresso Brasileiro de Sistemas Agroflorestais: SAFs - Desenvolvimento com proteção ambiental, Curitiba, Embrapa Florestas, 2004. p.452-454. (Documentos, 98).

SÁ, T.D. de A. Relatório Técnico CNPq 4. Projeto Tipitamba, ENV. 25, Belém-Pará, 2002, p. 12

SOMMER, R. Water and nutrient balance in deep soils under shifting cultivation with and without burning in the eastern Amazon. PhD (thesis) - Göttingen, Cuvillier, 2004. p.240.

; VLEK, P.L.G.; SÁ, T.D. de A.; COELHO, R.F.R. \& FOLSTER, H. Nutrient balance of shifiting cultivation by burning or mulching in the Eastern Amazon - evidence for sub-soil nutrient accumulation. Nutrient cycl. In agroecosyst., 2004. p. 68: 257-271

TIPPMANN, R; DENICH, M.;VIELHAUER, K. Integration of geo and remote sensing data for the assessment and monitoring of changes in smallholder land-use systems at farer level. In: GERMAN-BRAZILIAN WORKSHOP ON NEOTROPICAL ECOSYSTEMS ACHIEVEMENTS AND PROSPECTS OF COOPERATIVE RESEARCH, Abstracts, Hamburg, 2000. p.297.

WICKEL, B. Water and nutrient dynamics of a humid tropical watershed in Eastern Amazon. Center of Development Research, University of Bonn, Thesis of Doctor. Ecology and Development Series, n.21, 2004, 135p. 